\title{
Investigating the implicit and explicit attitudes of primary school educators in Scotland towards autistic children
}

Running title: Attitudes towards autism in Scottish educators

Eilidh Cage*1 $^{1}$ and Taylor Doyle ${ }^{1}$

${ }^{1}$ Department of Psychology, Faculty of Natural Sciences, University of Stirling

*Corresponding author information: Dr Eilidh Cage, University of Stirling, Stirling, Scotland, FK9 4LA, email: eilidh.cage@stir.ac.uk

\begin{abstract}
Background: Autistic children are frequently taught in mainstream schools, and it is imperative educators have appropriate knowledge and attitudes towards autism. In Scotland, policy aims for inclusion. However, there are few studies investigating Scottish educator's knowledge and attitudes towards autism, even though these could be a barrier to inclusion.

Aims: This study investigated Scottish educator's implicit and explicit attitudes towards autistic children. We also aimed to understand the relationships between attitudes, knowledge and experience.
\end{abstract}


Sample: Seventy primary school educators working in Scotland took part, with a mean age of 43. Most were female ( $n=64)$ and had on average 12 years' experience working in schools.

Methods: Participants completed a Single-Category Implicit Association Test (SC-IAT), to assess implicit attitudes towards autism. They also completed two explicit attitude measures (openness to autism and cognitive attitudes), and measures of autism knowledge and level of contact.

Results: Overall, participants held positive attitudes in explicit and implicit measures. Some participants (24\%) expressed negative implicit attitudes. There were correlations between explicit attitudes, age and years of experience, with older, more experienced staff having more negative attitudes. In regression analyses, greater autism knowledge predicted more positive explicit cognitive attitudes towards autistic children.

Conclusions: These findings indicate mostly positive attitudes in this sample. Younger educators with less experience may have more positive attitudes, perhaps reflecting societal changes in perceptions of autism. Greater knowledge predicted positive attitudes, suggesting that targeting knowledge may improve attitudes. Scotland's policies may have the potential to support the effective inclusion of autistic pupils in schools. 


\section{Introduction}

Autism is a neurodevelopmental condition characterised by difficulties and differences in social communication and social interaction, along with repetitive patterns of behaviour and focused interests (American Psychiatric Association, 2013). The inclusion of autistic ${ }^{1}$ children and young people in schools is vital, to ensure these pupils have the same educational opportunities as others (Pellicano et al., 2018). All-too-often, autistic pupils have negative experiences in mainstream schools, such as bullying (Sterzing et al., 2012), peer rejection (Rotheram-Fuller et al., 2010) and exclusions (Brede et al., 2017), including unlawful exclusions (Children in Scotland et al., 2018). The current study focused specifically on the Scottish context of inclusion for autistic pupils. In 2019, there were almost 20,000 autistic pupils recorded within Scottish schools, constituting approximately 3\% of all pupils (Scottish Government, 2020). Further, the number of autistic pupils doubled between 2012 and 2018, despite cuts in specialist staff and spending per pupil (Scottish Children's Services Coalition, 2019). This increase is likely due to better recognition, recording and changes in diagnostic criteria (Hansen et al., 2015; McConkey, 2020). Within this context, there have been efforts by the Scottish Government to ensure inclusion for autistic pupils.

First, Scottish educational policy adopts a "presumption of mainstreaming", with education within mainstream schools as the aim, and specialist schooling used only in exceptional circumstances (Standards in Scotland's Schools Etc. Act, 2000). Accordingly, most autistic pupils (84\%) in Scotland are educated in mainstream schools (Scottish Government, 2020). Second, the "Autism Toolbox", a free online resource for educators in Scotland, was initially developed in 2009 and updated in 2019 (Scottish Government \& Education Scotland, 2019), to provide resources on educating and including autistic pupils. However, local authorities are

\footnotetext{
${ }^{1}$ In this paper, we use identity-first language to respect the preferences of the autistic community (Kenny et al., 2016) and to avoid ableist discourse (Bottema-Beutel et al., 2020).
} 
responsible for promoting this resource and more needs to be done to ensure all educators receive training on support for autistic pupils (Children in Scotland et al., 2018). Further, there have been few empirical studies investigating the knowledge and attitudes of educators in Scotland.

In a mixed methods questionnaire completed by teachers in Scotland, around half expressed concerns about the integration of autistic pupils in the classroom, although greater experience related to more positive attitudes and confidence in teaching autistic children (McGregor \& Campbell, 2001). A qualitative study of students and tutors on a teacher education course at a Scottish university noted "basic" awareness of autism but little understanding of how to teach autistic pupils effectively (Ravet, 2018). Ravet (2018) also noted that only in the final year of the four-year course was a one-hour lecture about autism delivered. Teachers in Scotland have reported feeling there is lack of professional knowledge about autism, and they do not have the support needed to work with autistic pupils (Glashan et al., 2004).

Outside of Scotland, the literature supports the need to investigate educator's knowledge and attitudes towards autism. In a systematic review of barriers and facilitators to the inclusion of autistic pupils, knowledge of educators was noted as a substantial barrier to inclusion (Roberts \& Simpson, 2016). Humphrey \& Symes (2013) examined secondary school teacher's attitudes, experience, and knowledge in England. They reported high levels of inclusion, with higher levels of self-efficacy towards teaching autistic pupils amongst senior staff. Accordingly, educators play an important role in influencing the effective inclusion of autistic children into mainstream settings (Park \& Chitiyo, 2011). For example, educators with more positive attitudes may foster an inclusive environment, by promoting inclusive attitudes in peers (Kwon et al., 2017). 
Further, attitudes can be understood in several ways. An attitude may be stigmatising: discrediting a group or behaviours, often in relation to stereotypes and centred around "an undesired differentness" (Goffman, 1990, p.15). Having a stigmatising attitude can influence behavioural intentions - whereby one avoids or wants to maintain distance between themselves and the stigmatised individual (Gillespie-Lynch et al., 2015) or is not open to interacting with the stigmatised group (Nevill \& White, 2011). Further, there are cognitive attitudes in terms of thoughts and beliefs about autism. For example, in the classroom context educators might believe it is difficult to teach autistic children or believe negative stereotypes about autism (Lindsay et al., 2013). It is important to consider these different components of attitudes to gain a fuller understanding of potential barriers to inclusion.

Additionally, educators may hold negative implicit attitudes. Explicit attitudes consist of conscious thoughts that are easy to report and can be affected by social desirability (Kelly \& Barnes-Holmes, 2013). Implicit attitudes occur at a more subconscious level, potentially more accurately reflecting attitudes and being less influenced by social desirability (Echabe, 2013). The Implicit Association Test (IAT) can be used to measure implicit attitudes (Greenwald et al., 1998). The standard IAT examines biases to two opposing categories (for example, 'Black' and 'White'), assuming that response times will be faster for categories that the participant holds the strongest association (Greenwald et al., 1998). The Single-Category IAT (SC-IAT; Karpinski \& Steinman, 2006) measures associations with a single attitude object - and in the current study the SC-IAT examined implicit attitudes towards autism. Consideration of one category (rather than contrasting with an opposing category) provides a simple evaluation of attitudes towards a single target (Lautenbach \& Antoniewicz, 2018).

Some studies have used IAT approaches to look at implicit attitudes towards autism. In Ireland, Kelly and Barnes-Holmes (2013) used an Implicit Relational Assessment Procedure and found negative implicit biases towards autistic children. Using the standard IAT, Dickter et al., (2020) 
found negative implicit attitudes in a sample of non-autistic adults (recruited via Amazon's Mechanical Turk site) in the USA. Obeid et al. (2020) used the standard IAT to compare implicit attitudes towards autistic children and children with conduct disorder, in a sample of undergraduate students in the USA. They found the sample associated conduct disorder with more negative terms and autism with more positive terms. Finally, Wilson et al. (2019) used a single target IAT (conceptually similar to the SC-IAT) to assess implicit attitudes of Scottish teachers towards children with intellectual disability, finding neutral implicit attitudes towards this group (although autism is not an intellectual disability, they often co-occur; Kinnear et al., 2020).

Two variables that may relate to attitudes are knowledge and experience. With greater knowledge, educators may, for example, better understand an autistic child's ways of communicating, and have a greater appreciation of sensory sensitivities (Barnhill, 2016; Vincent \& Ralston, 2020). Segall \& Campbell (2012) surveyed 196 educational professionals in the USA and found many did not know the answers to knowledge questions and had not heard of different support strategies for autistic pupils. Able et al. (2015) found teachers in the USA felt it was necessary to obtain more knowledge about autism to create an inclusive classroom with individualised approaches. In other contexts, knowledge has also been found to relate to better attitudes (Gillespie-Lynch et al., 2015, 2019; Obeid et al., 2015).

Prior research indicates that experience or level of contact with autistic individuals relates to improved attitudes and knowledge. This relationship has been noted in teachers in mainstream schools (Segall \& Campbell, 2012), but also in studies investigating the general population's attitudes towards autism - indicating that the degree of contact can have a positive relationship with participants' attitudes (Gardiner \& Iarocci, 2014; Nevill \& White, 2011). These findings also fit with the assumptions of the contact hypothesis (Allport, 1954) - that contact with a 
stigmatised group can help to reduce stigma. It is therefore important to consider the role of experience in educator's attitudes towards autism.

Overall, the first aim of this study was to examine levels of explicit and implicit attitudes towards autism currently held by educators in Scotland. A second aim was to understand relationships between attitudes, knowledge and experience. Based on the literature described, it was predicted that self-reported explicit attitudes towards autistic children will be positive but given the mixed literature on implicit attitudes, we predict neutral implicit attitudes. It was also predicted that those with more knowledge and experience will have more positive attitudes. 


\section{Methods}

Participants

Seventy participants (Mean age $=42.9(S D=11.89$; range 20 to 66$)$ took part. Participants were recruited using adverts on social media and via personal contacts within primary schools. Most participants were female ( $n=64)$, had an average 12 years' experience in primary schools and worked in 19 different council areas across Scotland. Most were teachers (54.3\%) but a variety of other roles were represented (Table 1). Further demographic information such as ethnicity and level of education is presented in Table 1. Ethical approval was obtained from [BLINDED] and all participants gave informed consent prior to participation.

[Insert Table 1 here]

\section{Materials and procedure}

The study was presented online using the Gorilla experimental platform (www.gorilla.cc; Anwyl-Irvine et al., 2020), with data collected in April and May 2020. The study took around 20 minutes to complete. Participants first completed demographic questions (including questions about teaching experience and current roles), then the SC-IAT, followed by measures of openness towards autism, level of contact, autism knowledge and cognitive attitudes.

Implicit attitudes: Single-Category IAT (SC-IAT). This measure of implicit attitudes was adapted from Karpinski and Steinman (2006), aiming to evaluate implicit attitudes towards a single category ('autism'). In the SC-IAT, words appeared in the centre of the screen and participants had to categorise each word. First, participants completed 16 practice trials where they learned to associate words with the categories of 'good' and 'bad' and the appropriate key

presses (Figure 1), specifically, 'good' words with the letter 'e' and 'bad' words with the letter 'i'. The words were taken from Karpinski and Steinman (2006): positive words were wonderful, excellent, friendly, likeable, happy, triumphant, cheerful, pleasure and negative 
words were tragic, dislike, angry, humiliate, horrible, nasty, terrible, unpleasant. Participants used the keyboard to respond as quickly as possible to categorise words into the 'good' or 'bad' category. 'Good' always appeared on the left and 'bad' always appeared on the right.

\section{[Insert Figure 1 here]}

Participants then completed 24 practice and 72 experimental trials where they learned to associate the same key presses (the letter ' $i$ ' or 'e', depending on block) with words associated with 'autism'. The words used were autistic, Asperger's, spectrum, ASD, neurodiverse, based on Dickter et al. (2020). It was randomised whether the 'autism' category appeared on the left or right, therefore appearing either next to the word 'good' or 'bad'. If 'autism' was associated with 'good', this was the positive block, if it was associated with 'bad', this was the negative block (Figure 1). Following Karpinski and Steinman (2006), to avoid response bias, in experimental trials, autism, good and bad words were presented in a 7:7:10 (autism: good: bad) ratio so that $58 \%$ of correct responses were on the 'e' key in the positive block. In the negative block, autism words, good words and bad words were presented in a 7:10:7 ratio so $58 \%$ of responses were on the ' $\mathrm{i}$ ' key. After completing 72 experimental trails in one block, they completed another 24 practice and 72 experimental trails where associations were switched (e.g. they had to learn a new association for 'autism' with the opposite key press). Whether participants completed the positive or negative block first was counterbalanced.

Following Karpinski and Steinman (2006), non-responses were eliminated, and error responses were replaced with a penalty of the mean RT plus 400 milliseconds. Two participants' SC-IAT scores were excluded as they had error rates or non-response rates in over $20 \%$ of trials. The average error rate was $5.11 \%$, in line with error rates reported by Karpinski and Steinman (2006). Using the experimental blocks, D scores were calculated by subtracting the mean positive block RT from the mean negative block RT, and then dividing this by the standard 
deviation of total correct RTs. Following Wilson et al. (2019), a positive implicit attitude was indicated by $\mathrm{D}$ scores in the range of .16 to 2.00 , a neutral attitude by $\mathrm{D}$ scores ranging between -.15 to .15 , and a negative implicit attitude by $\mathrm{D}$ scores between -.16 to -2.00 .

Explicit attitudes: Openness towards autism. A vignette by Nevill \& White (2011) examined openness towards interacting with autistic children. The vignette was adapted to describe a child 'Jamie' (rather than a university student; Appendix 1). It was not explicitly stated that Jamie was autistic. Participants read the vignette followed by seven statements rated on a 5point Likert scale ('strongly disagree' (1) to 'strongly agree'(5)), such as 'I would feel comfortable teaching this child'. A total summed score was calculated with possible scores ranging from 7 to 35 , with higher scores indicating more openness. Internal reliability was very good (Cronbach's alpha $=.86)$.

Explicit attitudes: Cognitive attitudes. Barnes-Holmes et al.'s (2006) 10-item measure examined cognitive attitudes (thoughts and beliefs) about autistic children. Participants rated each item on a 5-point Likert scale (strongly disagree (1) to strongly agree (5)). Example items included 'typically-developing children are calmer and more flexible than autistic children'. Scores were summed, providing a total score ranging from 10 to 50. Barnes-Holmes et al. (2006) reported scores between 10 to 24 would indicate negative attitudes, 25 to 35 neutral, and 36 to 50 positive attitudes about autism. Internal reliability was good $(\alpha=.79)$.

Autism knowledge. Gillespie-Lynch et al.'s (2015) measure of autism knowledge was used, with thirteen items presented rated on a 5-point Likert scale ('strongly disagree' (-2) to 'strongly agree' (2)). Example items included 'autism is more frequently diagnosed in males than females'. Total knowledge was calculated by summing items, with possible scores ranging from -26 to 26 . Higher scores indicated more accurate knowledge of autism. Internal reliability was $\operatorname{good}(\alpha=.72)$. 
Level of contact report. An adapted version of Holmes et al.'s (1999) level of contact report measured level of contact with autistic individuals (previously adapted elsewhere e.g. Gardiner \& Iarocci, 2014; Morrison et al., 2019). Twelve items were presented and participants selected all items that applied to them. Example items included 'I provide services for autistic people'. The participant's score was the highest level of contact selected, giving an ordinal ranked variable. For example, the highest score would be 12 ('I am autistic') and the lowest score would be 1 ('I have never observed an autistic person'). No participants reported that they were autistic.

\section{Design and data analysis}

Descriptive statistics and correlations are presented to examine educator's explicit and implicit attitudes. Explicit attitudes were considered in terms of openness to autism and the attitudes towards autism scale, and implicit attitudes in terms of D scores from the SC-IAT. To examine relationships between attitudes, knowledge and experience, three multiple regression analyses were conducted. Within each, the attitude variable was the outcome: openness to autism (explicit behavioural intentions), attitudes towards autism scale (explicit cognitive attitudes) or SC-IAT scores (implicit attitudes). In each regression, knowledge and experience, both in terms of level of contact and experience of working in schools (years), were entered as predictors. Age was controlled for as correlations indicated this variable related to some of the variables in the regression. The other attitude variables were included due to shared variance between attitude measures. Assumptions for regression models were met (no multicollinearity, homoscedasticity, no influential outliers, errors independent). 


\section{Results}

Explicit and implicit attitudes towards autism

For openness, the mean score was 29.07 ( $S D=3.74$; range 11 to 35 ) out of a total possible score of 35 - indicating high levels of openness. For the attitudes towards autism scale (cognitive attitudes), the mean was 37.34 ( $S D=5.06$, range 26 to 48 ) out of a total possible score of 50 . This mean, according to Barnes-Holmes et al.'s (2006) categorisation, indicates a positive explicit attitude, with $58.6 \%(n=41)$ categorised as having a positive attitude and $41.4 \%(n=29)$ with a neutral attitude, and no participants with a negative attitude.

For the SC-IAT, the mean D score was $0.10(S D=0.41)$, indicating an overall neutral implicit attitude. However, there was a range of scores between -.73 and .93 , with a median D score of .17 (indicative of a positive implicit attitude), and inspection of the box plot (Figure 2) suggested most participants had positive implicit attitudes. Indeed, 51.5\% ( $n=35)$ had a D score categorised as positive, 25\% ( $n=17)$ had neutral and 23.5\% $(n=16)$ had negative implicit attitudes.

\section{[Insert Figure 2 here]}

For correlations between explicit and implicit attitude measures, only a significant correlation between the two explicit attitudes was noted, with no significant correlations between the implicit and explicit measures (see Table 2).

\section{[Insert Table 2 here]}

Relationships between attitudes, knowledge and experience

Mean autism knowledge was 15.89 ( $S D=4.49$, range 5 to 24$)$, out of a possible maximum score of 26 - indicating good autism knowledge. On average $82.5 \%$ of the knowledge questions were answered correctly ( $S D=13.85$, range $38.46 \%$ to $100 \%$ ). For level of contact, the most 
commonly reported level of contact was having an autistic relative $(24.3 \%, n=17$, rank=10), followed by providing services for autistic people $(21.4 \%, n=15$, rank=8) and living with an autistic person $(18.6 \%, n=13$, rank=11). The lowest level of contact reported was "frequently observing autistic individuals" $(n=1,1.4 \%$, rank=5). Mean years of experience working in schools was 12.16 ( $S D=9.44$, range 1 to 37 , median=9.50 years $)$.

As shown in Table 2, Pearson's correlations indicated significant positive relationships between autism knowledge and both explicit attitude measures, such that greater knowledge related to more positive explicit attitudes. Years of experience and age negatively correlated with cognitive attitudes, such that with more years of experience and older age, attitudes were more negative. Age negatively correlated with knowledge, such that older age related to less accurate knowledge.

Multiple regression with openness towards autism as the outcome variable, and cognitive attitudes, implicit attitude, knowledge, level of contact, years' experience and age as predictors, was conducted. Here, the model was not significant $(\mathrm{F}(6,67)=2.19, p=.057)$ nor were any predictors significant (all $p$ s $>$.074). Multiple regression with implicit attitudes (D scores) and the same predictors as above, was also not significant $(\mathrm{F}(6,67)=.87, p=.53)$ with no significant predictors (all ps>.16). However, multiple regression with cognitive attitudes as the outcome, was a significant model $(\mathrm{F}(6,67)=3.84, p=.003)$. Here, autism knowledge was the only significant predictor of cognitive attitudes (see Table 3), such that with increasing knowledge, there were more positive cognitive attitudes (Figure 3).

[Insert Table 3 here]

[Insert Figure 3 here] 


\section{Discussion}

This study investigated implicit and explicit attitudes towards autistic children in educators in Scotland. The results indicated positive attitudes overall, both explicitly and implicitly. A minority expressed negative implicit attitudes - which could indicate socially desirable answers were given within explicit measures. There were relationships between age, years of experience and attitudes, such that younger, less experienced participants had more positive cognitive attitudes. In regression analyses, only greater autism knowledge significantly predicted more positive cognitive attitudes. Together, these findings indicate some promising positive attitudes towards autism in this sample of educators in Scotland.

The first aim of this study was to examine explicit and implicit attitudes, hypothesising positive explicit attitudes and neutral implicit attitudes. Explicitly reported attitudes were positive in most participants, with a high level of openness and positive thoughts and beliefs towards autism. Indeed, in the measure of cognitive attitudes no participants were categorised with negative attitudes, with approximately $40 \%$ expressing neutral cognitive attitudes and the rest positive. These findings align with prior research which noted positive attitudes towards the inclusion of autistic pupils amongst educators in different countries (Humphrey \& Symes, 2013; Park \& Chitiyo, 2011). McGregor and Campbell's (2001) study of teacher's attitudes in Scotland did not use validated measures of attitudes but noted beliefs around autistic children being difficult to accommodate in the classroom. Prevalence and understanding of autism has changed substantially since McGregor and Campbell's (2001) study, making comparisons difficult. Larger, longitudinal studies would be beneficial to track attitudes over time using the same validated measures, and to establish whether positive attitudes in this study are reflected more widely. 
Just over half of the sample had positive implicit attitudes, with approximately a quarter each either expressing neutral or negative implicit attitudes. This finding contradicts our hypothesis of neutral implicit attitudes, and contrasts studies investigating implicit attitudes in the general population (Dickter et al., 2020), but supports work by Obeid et al. (2020) who noted positive implicit associations towards autism in undergraduate students. Kelly and Barnes-Holmes' (2013) study, which included a small sample of applied behaviour analysis (ABA) tutors and mainstream teachers, found negative implicit attitudes. The authors speculated that negative attitudes may relate to their sample working with autistic children with high support needs. The researchers' own approach may also have influenced their findings - for example, in their paper negative characteristics such as 'difficult' and 'unpleasant' are reported as being consistent with being autistic, and non-autistic children were framed as 'normally developing' (as opposed to more neutral terminology such as typically-developing or non-autistic). These views could inadvertently have endorsed ableism (Bottema-Beutel et al., 2020). Autism researchers researching stigma should be careful to avoid unintentionally endorsing stigma.

One similar study by Wilson et al. (2019) looked at Scottish teacher's implicit attitudes towards children with intellectual disabilities, using a Single Target IAT and noting neutral attitudes towards this group, with a wide range of D scores. In the current study, the mean D score indicated neutral attitudes, but closer inspection of the median and spread of data showed the majority (approximately 50\%) had positive implicit attitudes. Direct comparisons are needed to evaluate whether attitudes are more positive towards different developmental conditions, and Obeid et al. (2020) compared implicit attitudes towards conduct disorder and autism. They found more negative implicit attitudes towards conduct disorder, a condition related to behaviours that cause harm to others. Obeid et al. (2020) also speculated that diagnostic criteria for conduct disorder could be stigmatising. For autism, it would be worth 
considering whether endorsement of neurodiversity - which is arguably less stigmatising, focusing more on strengths and differences, while acknowledging challenges faced by autistic individuals (Kapp et al., 2013) - has any influence on attitudes towards autism. By extension, those who support neurodiversity may also have more positive attitudes towards other conditions.

While explicit attitude measures correlated, implicit and explicit measures did not. This finding is not unexpected, as other studies have also found no relationship between implicit and explicit measures (e.g. Obeid et al., 2020; Thibodeau \& Finley, 2016; Wilson et al., 2019; Wilson \& Scior, 2014). The lack of correlation may reflect the fact that the IAT is measuring attitudes accurately - whereas explicit measures are subject to manipulation so that the most positive attitudes are expressed and negative attitudes consciously suppressed (Thibodeau \& Finley, 2016). Thus, the implicit attitude could be unrelated to the explicit attitude if participants consciously chose to present the most socially desirable answers. This explanation fits with our data - with responses on the explicit measures overwhelmingly positive, almost a quarter expressed negative implicit attitudes, suggesting some suppression of negative attitudes was occurring in explicit measures.

Our second aim was to examine relationships between attitudes, knowledge and experience. There were significant correlations between cognitive attitudes, years teaching experience and participant's age (as well as knowledge, explored below). With increasing years of experience and increasing age, attitudes became more negative. This finding contrasts with McGregor and Campbell (2001), who found Scottish teachers with more experience reported more positive attitudes towards autism (although they did not use validated measures of attitudes). At the time of their study, McGregor and Campbell (2001) report only 780 autistic children recorded in Scottish schools - in comparison to almost 20,000 in 2019 (Scottish Government, 2020). Today, younger, less experienced educators may have an appreciation of 
autism influenced more by a different socio-cultural context to the early 2000 s. For example, an analysis of British newspapers between 1999 and 2008 highlighted often negative, misleading and inaccurate portrayals of autistic people (Huws \& Jones, 2011). In an analysis of US newspapers, Yu \& Farrell, (2020) noted stigmatising cues reduced over time between 1998 and 2013. In a study of university students in the USA, tested five years apart, White et al. (2019) noted the more recent cohort had more positive attitudes and better autism knowledge. Future research should examine how educators are influenced by wider sociocultural contexts and track how attitudes change over time.

In contrast to other studies (e.g. Nevill \& White, 2011), we did not find relationships between level of contact and attitudes. There was a high level of contact in our sample, with a quarter having an autistic relative, and only a few participants reporting little contact. Our sample is biased towards those with pre-existing personal experience, who may have taken part as they had a vested interest in the topic. However, we would perhaps still anticipate that high levels of contact would relate to attitudes or to knowledge, but this was not the case. It could be that the level of contact report does not capture quality of contact - which could still be variable even amongst those who have everyday proximity to autistic individuals (Gardiner \& Iarocci, 2014). Future research should consider both amount and quality of contact, to further understand how these variables contribute to attitudes.

Critically, in regression analyses only autism knowledge predicted more positive cognitive attitudes, suggesting that when controlling for other variables, knowledge remains to be a significant predictor of beliefs and thoughts about autism. This finding supports past research which has also noted a relationship between knowledge and attitudes (e.g. Gillespie-Lynch et al., 2015, 2019; Obeid et al., 2015). More accurate knowledge could challenge misconceptions and promote more positive thoughts about autism. However, there was no relationship between knowledge and behavioural intentions in this study. Given the 
relationship between behavioural intentions and stigma, such that lack of openness or willingness to interact with autistic individuals relates to characteristics of stigma (Cage et al., 2019; Gillespie-Lynch et al., 2015; Nevill \& White, 2011), it could be that these stigmatising attitudes are more complex and related to other variables, such as empathy and attitudes towards equality (Gillespie-Lynch et al., 2020). More research is needed in educational contexts to understand how individual characteristics contribute to educator's attitudes - doing so could help to identify specific targets for intervention.

\section{Limitations \& future research}

As highlighted, the sample was biased in consisting of those with high levels of contact. The participants were also predominantly female and White, limiting generalisability. Further, the findings are limited to primary school educators, and more research would be beneficial beyond primary school as autism is a life-long condition. In secondary school, autistic young people may experience more challenges as peer dynamics can be different and difficult (Cresswell et al., 2019). In qualitative research, autistic adolescents have described difficulties with secondary school teachers, such as being treated differently and receiving inconsistent support (Humphrey \& Lewis, 2008a, 2008b). Thus, research examining secondary school educator's perspectives and attitudes may be beneficial to identify ways of creating more positive secondary school environments for autistic pupils.

Another limitation is that we asked participants broadly about 'autism' and did not capture awareness and appreciation of heterogeneity within autism. For example, participants could be basing their understanding and attitudes on stereotypical perceptions of autism, and they could have different perceptions of autistic females. A study by Whitlock et al. (2020) presented primary school educators in the UK with vignettes describing autistic children and found participants less able to recognise autism in girls and showed a bias against autistic females. 
Since educators can have a role in recognising and referring autistic children for assessment and support (Whitlock et al., 2020), it is vital more research is conducted to ensure educators are more familiar with and understand heterogeneity within autistic individuals.

Although our findings indicated positive attitudes, it is not possible to tell whether this is directly due to Scotland's inclusive policies (e.g. The Scottish Strategy for Autism, Scottish Government, 2011). Further, our findings may only apply in Scotland, but it is vital that the social, cultural and political contexts are taken into account when attempting to understand non-autistic people's understanding and acceptance of autistic individuals. For example, one study found more autism knowledge in educator's in the UK compared to China, a country which does not have mandatory inclusion like the UK (Ballantyne et al., 2019). Further crosscultural and qualitative research may be beneficial to understand how these contexts may influence educators when it comes to the inclusion of autistic children.

Given these limitations, implications are noted with caution. Although explicit attitudes were positive, and knowledge reasonable, negative and neutral implicit attitudes were still present. We would therefore advocate for compulsory autism-specific training, and any training should be developed and delivered in collaboration with autistic people. Particularly, research should test whether focusing on neurodiversity and strengths-based approaches, rather than using deficit-focused approaches, can improve attitudes. Such research should examine whether attitudes translate into actual behaviour (Freitag \& Dunsmuir, 2015), and directly benefit autistic children and young people themselves. While some educators may argue that autism should not be singled out for training compared to other groups (Ravet, 2018), we argue autistic individuals are at a high risk of discrimination - for example, autistic individuals are at higher risk of bullying and victimisation (Schroeder et al., 2014; Sterzing et al., 2012), may be more likely to be excluded from school (Brede et al., 2017) and beyond school, autistic students have poor graduate outcomes (Association of Graduate Careers Advisory Services (AGCAS), 2018) 
and autistic adults are less likely to be in employment (Vincent \& Fabri, 2020). Accordingly, efforts are needed to specifically improve equality and inclusion for autistic people.

\section{Conclusion}

Overall, this study noted positive explicit and attitudes towards autism in a sample of primary school educators in Scotland. There were some negative and neutral implicit attitudes, suggesting some educators may selectively present explicitly positive attitudes but still have underlying negative beliefs. Knowledge about autism related to more positive cognitive attitudes towards autism, and continued efforts to ensure educators have up-to-date knowledge should be made. Educators play an important role in the inclusion of autistic pupils, to support equal opportunities for these individuals not only within education, but beyond.

\section{Data availability statement:}

The data that support the findings of this study are available from the corresponding author upon reasonable request.

\section{Acknowledgments:}

Thank you to all of the participants and people who shared this study. This study was conducted as part of the second author's Masters' Dissertation at the University of Stirling and received financial support from the Department of Psychology. 


\section{References}

Able, H., Sreckovic, M. A., Schultz, T. R., Garwood, J. D., \& Sherman, J. (2015). Views From the Trenches: Teacher and Student Supports Needed for Full Inclusion of Students With ASD. Teacher Education and Special Education, 38(1), 44-57. https://doi.org/10.1177/0888406414558096

Allport, G. W. (1954). The nature of prejudice. Addison-Wesley.

American Psychiatric Association. (2013). Diagnostic and Statistical Manual of Mental Disorders (Fifth edition). American Psychiatric Publishing.

Anwyl-Irvine, A. L., Massonnié, J., Flitton, A., Kirkham, N., \& Evershed, J. K. (2020). Gorilla in our midst: An online behavioral experiment builder. Behavior Research Methods, 52(1), 388-407. https://doi.org/10.3758/s13428-019-01237-x

Association of Graduate Careers Advisory Services (AGCAS). (2018). A report on the first destinations of 2016 disabled graduates. Accessed 18th December 2018. What happens next? https://www.agcas.org.uk/Knowledge-Centre/7991a7d5-84a0-4fe1bbdc-5313d9039486

Ballantyne, C., Gillespie-Smith, K., \& Wilson, C. (2019). A Comparison of Knowledge and Experience of Autism Spectrum Disorder among Teachers in the United Kingdom and China. International Journal of Disability, Development and Education, O(0), 112. https://doi.org/10.1080/1034912X.2019.1674254

Barnes-Holmes, D., Barnes-Holmes, Y., Power, P., Hayden, E., Milne, R., \& Stewart, I. (2006). Do you really know what you believe? Developing the Implicit Relational Assessment Procedure (IRAP) as a direct measure of implicit beliefs. The Irish Psychologist, 32(7), 169-177. Scopus. 
Barnhill, G. P. (2016). Supporting Students With Asperger Syndrome on College Campuses: Current Practices. Focus on Autism and Other Developmental Disabilities, 31(1), 315. https://doi.org/10.1177/1088357614523121

Bottema-Beutel, K., Kapp, S. K., Lester, J. N., Sasson, N. J., \& Hand, B. N. (2020). Avoiding Ableist Language: Suggestions for Autism Researchers. Autism in Adulthood. https://doi.org/10.1089/aut.2020.0014

Brede, J., Remington, A., Kenny, L., Warren, K., \& Pellicano, E. (2017). Excluded from school: Autistic students' experiences of school exclusion and subsequent reintegration into school. Autism \& Developmental Language Impairments, 2 , 2396941517737511. https://doi.org/10.1177/2396941517737511

Cage, E., Di Monaco, J., \& Newell, V. (2019). Understanding, attitudes and dehumanisation towards autistic people. Autism, 23(6), 1373-1383. https://doi.org/10.1177/1362361318811290

Children in Scotland, National Autistic Society Scotland, \& Scottish Autism. (2018). Not included, not engaged, not involved: A report on the experiences of autistic children missing school. https://www.notengaged.com/

Cresswell, L., Hinch, R., \& Cage, E. (2019). The experiences of peer relationships amongst autistic adolescents: A systematic review of the qualitative evidence. Research in Autism Spectrum Disorders, 61, 45-60. https://doi.org/10.1016/j.rasd.2019.01.003

Dickter, C. L., Burk, J. A., Zeman, J. L., \& Taylor, S. C. (2020). Implicit and Explicit Attitudes Toward Autistic Adults. Autism in Adulthood, 2(2), 144-151. https://doi.org/10.1089/aut.2019.0023 
Echabe, A. (2013). Relationship Between Implicit and Explicit Measures of Attitudes: The Impact of Application Conditions. Europe's Journal of Psychology, 9(2), 231-245. https://doi.org/10.5964/ejop.v9i2.544

Freitag, S., \& Dunsmuir, S. (2015). The Inclusion of Children with ASD: Using the Theory of Planned Behaviour as a Theoretical Framework to Explore Peer Attitudes. International Journal of Disability, Development and Education, 62(4), 405-421. https://doi.org/10.1080/1034912X.2015.1046818

Gardiner, E., \& Iarocci, G. (2014). Students with Autism Spectrum Disorder in the University Context: Peer Acceptance Predicts Intention to Volunteer. Journal of Autism and Developmental Disorders, 44(5), 1008-1017. https://doi.org/10.1007/s10803-013$1950-4$

Gillespie-Lynch, K., Brooks, P. J., Someki, F., Obeid, R., Shane-Simpson, C., Kapp, S. K., Daou, N., \& Smith, D. S. (2015). Changing College Students' Conceptions of Autism: An Online Training to Increase Knowledge and Decrease Stigma. Journal of Autism and Developmental Disorders, 45(8), 2553-2566. https://doi.org/10.1007/s10803$015-2422-9$

Gillespie-Lynch, K., Daou, N., Obeid, R., Reardon, S., Khan, S., \& Goldknopf, E. J. (2020). What Contributes to Stigma Towards Autistic University Students and Students with Other Diagnoses? Journal of Autism and Developmental Disorders, 1-17. https://doi.org/10.1007/s10803-020-04556-7

Gillespie-Lynch, K., Daou, N., Sanchez-Ruiz, M.-J., Kapp, S. K., Obeid, R., Brooks, P. J., Someki, F., Silton, N., \& Abi-Habib, R. (2019). Factors underlying cross-cultural differences in stigma toward autism among college students in Lebanon and the United States. Autism, 23(8), 1993-2006. https://doi.org/10.1177/1362361318823550 
Glashan, L., Mackay, G., \& Grieve, A. (2004). Teachers' Experience of Support in the Mainstream Education of Pupils with Autism. Improving Schools, 7(1), 49-60. https://doi.org/10.1177/1365480204042113

Goffman, E. (1990). Stigma: Notes on the management of spoiled identity (3rd ed.). Penguin Books.

Greenwald, A. G., McGhee, D. E., \& Schwartz, J. L. K. (1998). Measuring individual differences in implicit cognition: The implicit association test. Journal of Personality and Social Psychology, 74(6), 1464-1480. https://doi.org/10.1037/00223514.74.6.1464

Hansen, S. N., Schendel, D. E., \& Parner, E. T. (2015). Explaining the Increase in the Prevalence of Autism Spectrum Disorders: The Proportion Attributable to Changes in Reporting Practices. JAMA Pediatrics, 169(1), 56-62. https://doi.org/10.1001/jamapediatrics.2014.1893

Holmes, E. P., Corrigan, P. W., Williams, P., Canar, J., \& Kubiak, M. A. (1999). Changing Attitudes About Schizophrenia. Schizophrenia Bulletin, 25(3), 447-456. https://doi.org/10.1093/oxfordjournals.schbul.a033392

Humphrey, N., \& Lewis, S. (2008a). 'Make me normal': The views and experiences of pupils on the autistic spectrum in mainstream secondary schools. Autism, 12(1), 23-46. https://doi.org/10.1177/1362361307085267

Humphrey, N., \& Lewis, S. (2008b). What does 'inclusion' mean for pupils on the autistic spectrum in mainstream secondary schools? Journal of Research in Special Educational Needs, 8(3), 132-140. https://doi.org/10.1111/j.1471-3802.2008.00115.x 
Humphrey, N., \& Symes, W. (2013). Inclusive education for pupils with autistic spectrum disorders in secondary mainstream schools: Teacher attitudes, experience and knowledge. International Journal of Inclusive Education, 17(1), 32-46. https://doi.org/10.1080/13603116.2011.580462

Huws, J. C., \& Jones, R. S. P. (2011). Missing voices: Representations of autism in British newspapers, 1999-2008. British Journal of Learning Disabilities, 39(2), 98-104. https://doi.org/10.1111/j.1468-3156.2010.00624.x

Kapp, S. K., Gillespie-lynch, K., Sherman, L. E., \& Hutman, T. (2013). Deficit, Difference, or Both? Autism and Neurodiversity. Developmental Psychology, 49(1), 59-71. https://doi.org/10.1037/a0028353

Karpinski, A., \& Steinman, R. B. (2006). The Single Category Implicit Association Test as a measure of implicit social cognition. Journal of Personality and Social Psychology, 91(1), 16-32. https://doi.org/10.1037/0022-3514.91.1.16

Kelly, A., \& Barnes-Holmes, D. (2013). Implicit attitudes towards children with autism versus normally developing children as predictors of professional burnout and psychopathology. Research in Developmental Disabilities, 34(1), 17-28. https://doi.org/10.1016/j.ridd.2012.07.018

Kinnear, D., Rydzewska, E., Dunn, K., Hughes-McCormack, L., Melville, C., Henderson, A., \& Cooper, S.-A. (2020). The relative influence of intellectual disabilities and autism on sensory impairments and physical disability: A whole-country cohort of 5.3 million children and adults. Journal of Applied Research in Intellectual Disabilities, 33(5), 1059-1068. https://doi.org/10.1111/jar.12728

Kwon, K.-A., Hong, S.-Y., \& Jeon, H.-J. (2017). Classroom Readiness for Successful Inclusion: Teacher Factors and Preschool Children's Experience With and Attitudes 
Toward Peers With Disabilities. Journal of Research in Childhood Education, 31(3), 360-378. https://doi.org/10.1080/02568543.2017.1309480

Lautenbach, F., \& Antoniewicz, F. (2018). Ambivalent implicit attitudes towards inclusion in preservice PE teachers: The need for assessing both implicit and explicit attitudes towards inclusion. Teaching and Teacher Education, 72, 24-32. https://doi.org/10.1016/j.tate.2018.01.003

Lindsay, S., Proulx, M., Thomson, N., \& Scott, H. (2013). Educators' Challenges of Including Children with Autism Spectrum Disorder in Mainstream Classrooms. International Journal of Disability, Development and Education, 60(4), 347-362. https://doi.org/10.1080/1034912X.2013.846470

McConkey, R. (2020). The rise in the numbers of pupils identified by schools with autism spectrum disorder (ASD): A comparison of the four countries in the United Kingdom. Support for Learning, 35(2), 132-143. https://doi.org/10.1111/1467-9604.12296

McGregor, E., \& Campbell, E. (2001). The Attitudes of Teachers in Scotland to the Integration of Children with Autism into Mainstream Schools. Autism, 5(2), 189-207. https://doi.org/10.1177/1362361301005002008

Morrison, K. E., DeBrabander, K. M., Faso, D. J., \& Sasson, N. J. (2019). Variability in first impressions of autistic adults made by neurotypical raters is driven more by characteristics of the rater than by characteristics of autistic adults. Autism, 23(7), 1817-1829. https://doi.org/10.1177/1362361318824104

Nevill, R. E. A., \& White, S. W. (2011). College Students' Openness Toward Autism Spectrum Disorders: Improving Peer Acceptance. Journal of Autism and Developmental Disorders, 41(12), 1619-1628. https://doi.org/10.1007/s10803-011$1189-\mathrm{x}$ 
Obeid, R., Bisson, J. B., Cosenza, A., Harrison, A. J., James, F., Saade, S., \& GillespieLynch, K. (2020). Do Implicit and Explicit Racial Biases Influence Autism Identification and Stigma? An Implicit Association Test Study. Journal of Autism and Developmental Disorders. https://doi.org/10.1007/s10803-020-04507-2

Obeid, R., Daou, N., DeNigris, D., Shane-Simpson, C., Brooks, P. J., \& Gillespie-Lynch, K. (2015). A Cross-Cultural Comparison of Knowledge and Stigma Associated with Autism Spectrum Disorder Among College Students in Lebanon and the United States. Journal of Autism and Developmental Disorders, 45(11), 3520-3536. https://doi.org/10.1007/s10803-015-2499-1

Park, M., \& Chitiyo, M. (2011). An examination of teacher attitudes towards children with autism. Journal of Research in Special Educational Needs, 11(1), 70-78. https://doi.org/10.1111/j.1471-3802.2010.01181.x

Pellicano, L., Bölte, S., \& Stahmer, A. (2018). The current illusion of educational inclusion. Autism, 22(4), 386-387. https://doi.org/10.1177/1362361318766166

Ravet, J. (2018). 'But how do I teach them?': Autism \& Initial Teacher Education (ITE). International Journal of Inclusive Education, 22(7), 714-733. https://doi.org/10.1080/13603116.2017.1412505

Roberts, J., \& Simpson, K. (2016). A review of research into stakeholder perspectives on inclusion of students with autism in mainstream schools. International Journal of Inclusive Education, 20(10), 1084-1096. https://doi.org/10.1080/13603116.2016.1145267

Rotheram-Fuller, E., Kasari, C., Chamberlain, B., \& Locke, J. (2010). Social involvement of children with autism spectrum disorders in elementary school classrooms. Journal of 
Child Psychology and Psychiatry, 51(11), 1227-1234. https://doi.org/10.1111/j.14697610.2010.02289.x

Schroeder, J. H., Cappadocia, M. C., Bebko, J. M., Pepler, D. J., \& Weiss, J. A. (2014). Shedding Light on a Pervasive Problem: A Review of Research on Bullying Experiences Among Children with Autism Spectrum Disorders. Journal of Autism and Developmental Disorders, 44(7), 1520-1534. https://doi.org/10.1007/s10803013-2011-8

Scottish Children's Services Coalition. (2019). The number of pupils identified with autism, dyslexia and other conditions has increased dramatically, reinforcing calls for greater support. https://www.thescsc.org.uk/the-number-of-pupils-identified-withautism-dyslexia-and-other-conditions-has-increased-dramatically-reinforcing-callsfor-greater-support/

Scottish Government. (2011). The Scottish Strategy for Autism-Gov.scot. https://www.gov.scot/publications/scottish-strategy-autism/

Scottish Government. (2020). Pupil census: Supplementary statistics. https://www.gov.scot/publications/pupil-census-supplementary-statistics/

Scottish Government, \& Education Scotland. (2019). Autism Toolbox. http://www.autismtoolbox.co.uk/about-autism-toolbox

Standards in Scotland's Schools etc. Act, (2000). https://www.legislation.gov.uk/asp/2000/6/contents

Segall, M. J., \& Campbell, J. M. (2012). Factors relating to education professionals' classroom practices for the inclusion of students with autism spectrum disorders. 
Research in Autism Spectrum Disorders, 6(3), 1156-1167.

https://doi.org/10.1016/j.rasd.2012.02.007

Sterzing, P. R., Shattuck, P. T., Narendorf, S. C., Wagner, M., \& Cooper, B. P. (2012).

Bullying Involvement and Autism Spectrum Disorders: Prevalence and Correlates of Bullying Involvement Among Adolescents With an Autism Spectrum Disorder. Archives of Pediatrics \& Adolescent Medicine, 166(11), 1058. https://doi.org/10.1001/archpediatrics.2012.790

Thibodeau, R., \& Finley, J. R. (2016). On Associative Stigma: Implicit and Explicit Evaluations of a Mother of a Child with Autism Spectrum Disorder. Journal of Child and Family Studies, 3(26), 843-850. https://doi.org/10.1007/s10826-016-0615-2

Vincent, J., \& Fabri, M. (2020). The Ecosystem of Competitive Employment for University Graduates with Autism. International Journal of Disability, Development and Education, O(0), 1-17. https://doi.org/10.1080/1034912X.2020.1821874

Vincent, J., \& Ralston, K. (2020). Trainee teachers' knowledge of autism: Implications for understanding and inclusive practice. Oxford Review of Education, 46(2), 202-221. https://doi.org/10.1080/03054985.2019.1645651

White, D., Hillier, A., Frye, A., \& Makrez, E. (2019). College students’ knowledge and attitudes towards students on the autism spectrum. Journal of Autism and Developmental Disorders, 49, 2699-2705. https://doi.org/10.1007/s10803-016-28181

Whitlock, A., Fulton, K., Lai, M.-C., Pellicano, E., \& Mandy, W. (2020). Recognition of Girls on the Autism Spectrum by Primary School Educators: An Experimental Study. Autism Research, 13(8), 1358-1372. https://doi.org/10.1002/aur.2316 
Wilson, C., Woolfson, L. M., \& Durkin, K. (2019). The impact of explicit and implicit teacher beliefs on reports of inclusive teaching practices in Scotland. International Journal of Inclusive Education, O(0), 1-19.

https://doi.org/10.1080/13603116.2019.1658813

Wilson, M. C., \& Scior, K. (2014). Attitudes towards individuals with disabilities as measured by the Implicit Association Test: A literature review. Research in Developmental Disabilities, 35(2), 294-321.

https://doi.org/10.1016/j.ridd.2013.11.003

Yu, N., \& Farrell, L. (2020). Autism in the media: A longitudinal study of stigma cues and framing of attribution. Newspaper Research Journal, 41(4), 489-505. https://doi.org/10.1177/0739532920969887 
Table 1

Demographic Information on participants, including details about school experience

\section{Percentage}

Ethnicity

White British

Other White Background

Mixed Ethnicity

Prefer not to say

Employment

Full-time 71.4

Part-time

20.0

Student

7.14

Other

Highest level of education

1-4 Standard Grades/GCSEs equivalent

5+ Standard Grades/GCSEs equivalent

$2+$ Scottish Higher/A-levels or equivalent

Undergraduate degree

Masters degree

$\mathrm{PhD}$

Other qualifications

Job title

Primary teacher

Classroom assistant

Head teacher

Deputy head teacher

Principle teacher

Educational Psychologist

Other*

14.3

*Including sports coaches, administrative staff, and outreach workers. 
Table 2.

Correlations between explicit (openness and attitudes to autism scale) and implicit attitudes (D scores), experience (level of contact, years working in schools), autism knowledge, participant age and gender.

\begin{tabular}{|c|c|c|c|c|c|c|c|c|c|c|c|c|c|c|}
\hline & \multicolumn{2}{|c|}{ Openness } & \multicolumn{2}{|c|}{$\begin{array}{l}\text { Attitudes to } \\
\text { autism scale }\end{array}$} & \multicolumn{2}{|c|}{ D score } & \multicolumn{2}{|c|}{ Level of contact } & \multicolumn{2}{|c|}{$\begin{array}{c}\text { Autism } \\
\text { knowledge }\end{array}$} & \multicolumn{2}{|c|}{$\begin{array}{l}\text { Years' experience } \\
\text { in schools }\end{array}$} & \multicolumn{2}{|c|}{ Age } \\
\hline & $r$ & $p$ & $r$ & $p$ & $r$ & $p$ & $r$ & $p$ & $r$ & $p$ & $r$ & $p$ & $r$ & $p$ \\
\hline $\begin{array}{l}\text { Attitudes to } \\
\text { autism scale }\end{array}$ & .31 & $.010 * *$ & & & & & & & & & & & & \\
\hline $\begin{array}{l}\text { D score (implicit } \\
\text { attitudes) }\end{array}$ & .15 & .21 & .010 & .94 & & & & & & & & & & \\
\hline Level of contact & .11 & .38 & .099 & .42 & & .076 & & & & & & & & \\
\hline $\begin{array}{c}\text { Autism } \\
\text { knowledge }\end{array}$ & .28 & $.019 *$ & .43 & $<.001 * * *$ & .13 & .29 & .22 & .073 & & & & & & \\
\hline $\begin{array}{c}\text { Years' } \\
\text { experience }\end{array}$ & .064 & .60 & -.24 & $.043 *$ & .076 & .54 & .034 & .78 & -.15 & .20 & & & & \\
\hline Age & -.13 & .28 & 32 & $.007 * *$ & .069 & .58 & .073 & .55 & -.27 & $.025^{*}$ & .66 & $<.001 * * *$ & & \\
\hline Gender & .18 & .13 & .14 & .26 & .086 & .49 & .17 & .16 & .10 & .41 & .097 & .44 & -.21 & .075 \\
\hline
\end{tabular}


Table 3.

Regression model with cognitive attitudes as the outcome variable, and openness, implicit attitudes, knowledge, level of contact, years' experience and age as predictors.

\begin{tabular}{llllll}
\hline & B & B CI & SE B & $\boldsymbol{\beta}$ & $\boldsymbol{p}$ \\
\hline Openness & .29 & {$[-.029-.61]$} & .16 & .21 & .074 \\
$\begin{array}{l}\text { Implicit } \\
\text { attitudes }\end{array}$ & -.69 & {$[-3.54-2.17]$} & 1.43 & -.054 & .63 \\
$\begin{array}{l}\text { Knowledge } \\
\text { Level of }\end{array}$ & .36 & {$[.091-.64]$} & .14 & .32 & .010 \\
contact & .11 & {$[-.65-.87]$} & .38 & .032 & .78 \\
$\begin{array}{l}\text { Years } \\
\text { experience }\end{array}$ & -.073 & {$[-.24-.091]$} & .082 & -.14 & .38 \\
$\begin{array}{l}\text { Age } \\
\text { Note: B = unstandardised beta coefficient, B CI = confidence intervals at 95\% lower and }\end{array}$ & \\
\hline
\end{tabular}




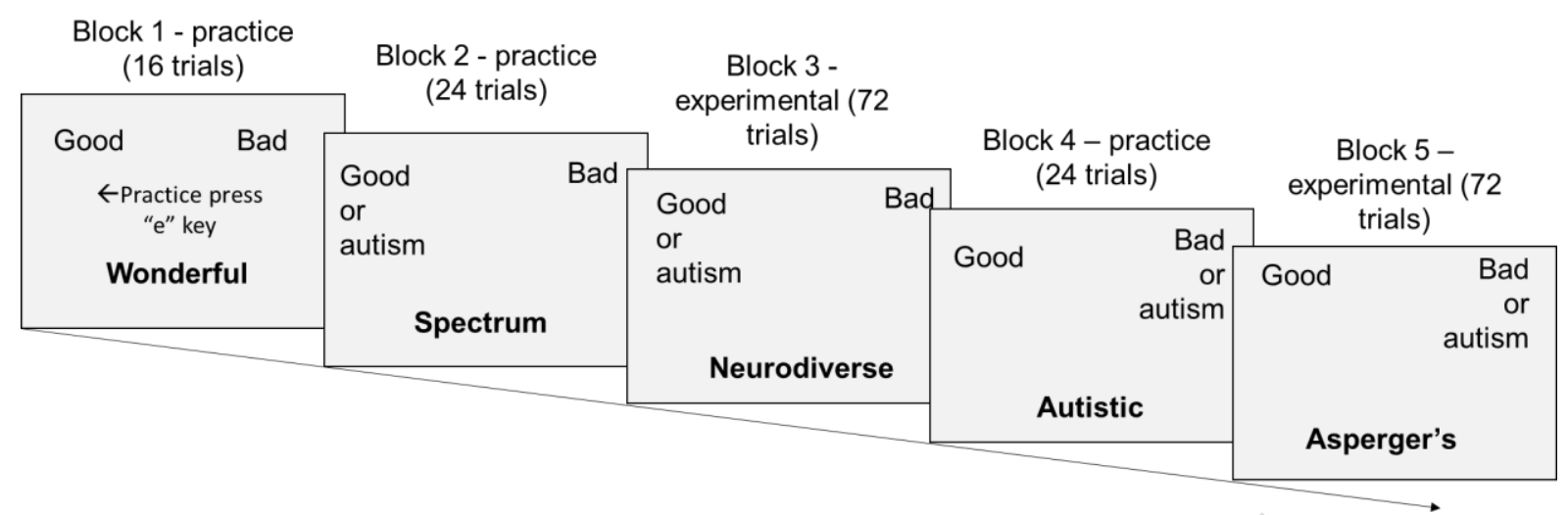

Figure 1. Experimental procedure for the Single Category IAT. The experimental blocks were randomized so that participants either saw the 'good' or 'bad' associations first. 


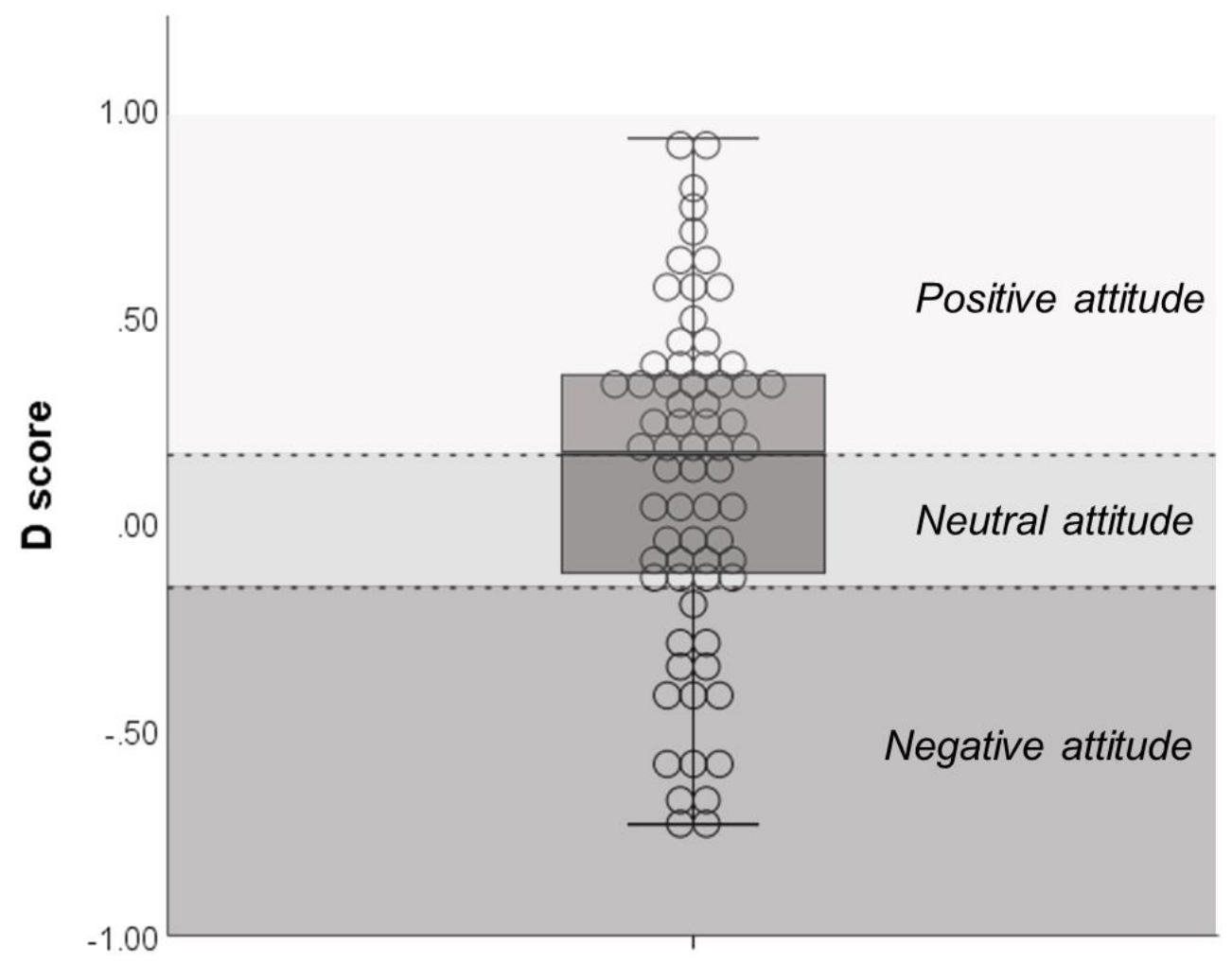

Figure 2. Box plot of D scores from the Single Category Implicit Association Task (SC-IAT). Positive implicit attitudes were indicated by D scores above .16, neutral implicit attitudes by D scores between -.15 and .15, and negative implicit attitudes by D scores less than -.16. 


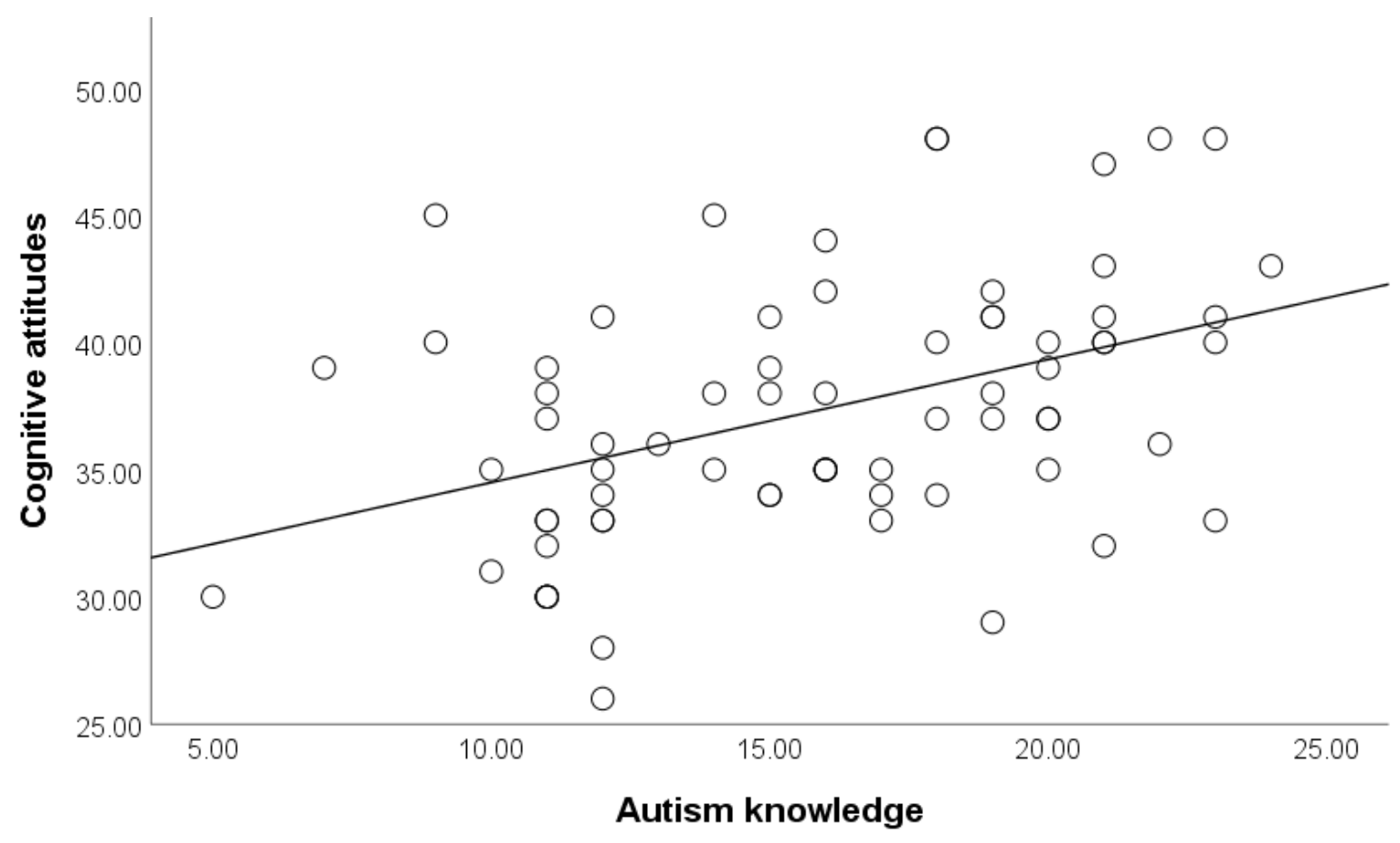

Figure 3. Scatterplot showing the relationship between cognitive attitudes and autism knowledge. 


\section{Appendix 1.}

Jamie is a new pupil at your school. Jamie does not spend time with, or talk with, other children and finds it hard to make friends. Jamie is mostly very quiet. When Jamie speaks or does things, they are usually done over and over again. For example, when telling you a joke, Jamie may repeat the punch line over and over again. Jamie does not usually show signs of happiness, sadness, or fear and sometimes has a confused facial expression when walking around the playground or talking to people. When in the classroom, Jamie usually spends a great deal of time sitting in a chair and rocking back and forth. Jamie also likes to always have a book in-hand and occasionally reads it while walking. Jamie is a good pupil and is quite generous with time and possessions. Jamie is always willing to help others out with their work when they ask for it. 